\title{
Resposta de cultivares de alface à salinidade da solução nutritiva com rejeito salino em hidroponia
}

\author{
Nildo da S. Dias ${ }^{1}$, O svaldo N. de Sousa Neto ${ }^{1}$, Christiano R. Cosme ${ }^{1}$,

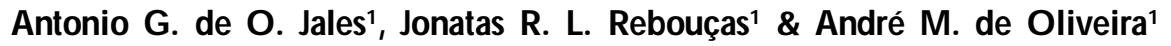

RESU M O

No processo de dessalinização se gera, além da água potável, um rejeito altamente salino e de poder poluente elevado, o qual pode ser utilizado na produção agrícola rentável dependendo da adoção de práticas culturais adequadas e da tolerância das plantas às condições salinas. Nos últimos anos a tendência tem sido a substituição da agricultura convencional por sistemas hidropônicos de cultivos, considerados um dos mais eficientes no uso de água. 0 objetivo desta pesquisa foi analisar a resposta de duas cultivares de alface sob sistema hidropônico de cultivo (Lactuca sativa L., cvs. Verônica e Babá de verão) em diferentes níveis de salinidade da solução nutritiva preparadas com água de abastecimento, água de rejeito coletada no dessalinizador e da sua diluição com água de abastecimento a 75, 50 e $25 \%$, resultando em condutividades elétricas da solução nutritiva (CEs) de 1,$1 ; 2,4 ; 3,6 ; 4,7$ e 5,7 dS m$^{-1}$ após as diluições e adição de fertilizantes. O correu variação genotípica sob as variáveis de crescimento e produção da alface, exceto para o número de folhas, sendo a cultivar Babá de verão a que produziu maior rendimento, independentemente do nível de salinidade e, portanto, a cultivar mais tolerante à salinidade da água com rejeito salino.

Palavras-chave: osmose reversa, reúso de água e nutrição de plantas

\section{Response of lettuce cultivars to nutrient solution salinity with saline rejects in hydropony}

\begin{abstract}
In desalination process, besides the potable water, highly salty and polluted water (brine) is generated, which can be used for producing profitable crops depending on the adequate cultural practices as well as on the plant ability of reacting to saline conditions. The trend in recent years has been towards conversion of conventional agriculture to soilless agriculture which is considered to be a more efficient use of water system. The aim of this research was to examine the response of two lettuce cultivars (Lactuca sativa L. cvs. Veronica, Babá de verão) under hydroponic system to different levels of salinity of the nutrient solutions prepared with tap water, reject from desalination plant, and its dilution with tap water at 75,50 and $25 \%$, giving a range of electrical conductivities of the nutrient solution (ECs) of 1.1, 2.4, 3.6, 4.7 and $5.7 \mathrm{dS} \mathrm{m}^{-1}$ after the dilutions and fertilizer addition. Genotypic variation for all analysed variables except number of leaves was observed, and the cultivar Babá de verão produced higher yield regardless of salinity level, therefore more tolerant to water salinity with saline rejects.
\end{abstract}

Key words: reverse osmosis, water reuse, plant nutrition 


\section{INTRODUÇÃO}

No semiárido brasileiro, devido à reconhecida escassez de águas superficiais o grande desafio é promover o abastecimento de água às famílias rurais e garantir a produção de alimentos. $\mathrm{O}$ uso de águas subterrâneas é uma alternativa viável para garantir o acesso dessas comunidades à água, a partir de investimentos públicos na perfuração de poços tubulares; entretanto, essas fontes hídricas apresentam, na maioria dos casos, restrições de uso para o consumo humano (Ayers \& Westcot, 1999), por apresentarem problemas de salinidade.

O tratamento amplamente utilizado para reduzir a concentração de sais dessas águas tem sido a dessalinização por osmose reversa (Amorim et al., 2004). Faz-se necessário, porém, que se considerem os riscos ambientais decorrentes desta técnica visto que, na dessalinização se gera, além da água potável, uma água residuária (rejeito) altamente salina e com risco de contaminação ambiental elevado.

Desta forma e embora a dessalinização seja uma técnica incremental ao bem-estar dessas comunidades rurais, deve-se ponderar pela dualidade de seu benefício em virtude do potencial de contaminação da água residuária gerada neste processo, que necessita ser utilizada de forma ambientalmente correta possibilitando, sempre que possível, a produção de alimentos.

No Brasil, o rejeito da dessalinização não está recebendo, na quase totalidade dos casos, qualquer tratamento; mesmo assim, está sendo despejado no solo, propiciando alto acúmulo de sais nas camadas superficiais do terreno (Porto et al., 2001). Riley et al. (1997) consideraram o cultivo de plantas halófitas a melhor opção para dispor o rejeito da osmose reversa; já Soares et al. (2006) afirmam que o uso do rejeito para irrigação de plantas halófitas forrageiras pode ser incompatível com a seguridade ambiental em razão da ineficiência de extração de sais dessas plantas frente ao montante aplicado ao solo.

Uma opção para se dispor o rejeito da dessalinização é a sua utilização na solução nutritiva em cultivos hidropônicos de hortaliças, já que a tolerância das plantas à salinidade em sistemas hidropônicos é maior em relação ao sistema convencional, pois a inexistência do potencial mátrico sobre o potencial total da água irá reduzir a dificuldade de absorção de água pelas plantas (Soares, 2007). Além disso, no sistema hidropônico o rejeito da dessalinização de água já está captado, podendo ser diluído para recirculação e irrigar outras culturas ou, ainda, ser facilmente direcionado para concentração em tanques de evaporação, evitando seu despejo no solo.

Estudos realizados sobre a tolerância de várias espécies à salinidade em sistema hidropônico de cultivo têm demonstrado que, mediante manejos adequados da água e das práticas de cultivo, pode-se produzir comercialmente com água salina (Caruso \& Villari, 2004; Savvas et al., 2007; Al-Karaki et al., 2009). Neste sentido, espera-se que em sistemas hidropônicos culturas sobretudo de ciclo rápido, proporcionem o uso sustentável de águas residuárias do processo de dessalinização garantido também a produção de alimentos para as comunidades em que têm sido implantadas as estações de tratamento.
Levando-se em consideração esses aspectos objetivou-se investigar como a salinidade da solução nutritiva obtida com ou sem a necessidade de diluição da água de rejeito gerado pela osmose reversa, influencia a produção de duas cultivares de alface hidropônica.

\section{Material e MÉTOdos}

O experimento foi realizado no período de abril a junho de 2008, em um ambiente protegido do Departamento de Ciências Ambientais da Universidade Federal Rural do Semiárido, localizado em Mossoró, RN (5 $5^{\circ}$ 11' S, 37 $7^{\circ} 20^{\prime} \mathrm{W}$ e $18 \mathrm{~m}$ ).

Estudou-se a resposta de duas cultivares de alface sob sistema hidropônico de cultivo (Lactuca sativa L., cvs. Verônica e Babá de verão) em diferentes níveis de salinidade da solução nutritiva preparada misturando-se água de abastecimento proveniente do campus da UFERSA, com água de rejeito coletada no dessalinizador, nas seguintes proporções: $100 \%$ água de abastecimento (do campus da UFERSA); $25 \%$ água de rejeito $+75 \%$ água de abastecimento; $50 \%$ água de rejeito $+50 \%$ água de abastecimento; $75 \%$ água de rejeito $+25 \%$ água de abastecimento e $100 \%$ água de rejeito coletada no dessalinizador, resultando em condutividades elétricas da solução nutritiva (CEs), respectivamente de: 1,$1 ; 2,4 ; 3,6 ; 4,7$ e $5,7 \mathrm{dS} \mathrm{\textrm {m } ^ { - 1 }}$ após as diluições e adição de fertilizantes. O delineamento experimental foi o de blocos casualizados completos em parcelas subdivididas, com quatro repetições.

A quantidade de fertilizantes adicionados à solução nutritiva ( $\mathrm{g} \mathrm{L}^{-1}$ ) foi: 0,$5 ; 0,37 ; 0,14$ e 27 de nitrato de cálcio, nitrato de potássio, fosfato monoamônico, sulfato de magnésio, respectivamente, e como fonte de micronutrientes adicionouse $0,06 \mathrm{~g} \mathrm{~L}^{-1}$ de Quelatec $®$ (mistura sólida de EDTA-chelated nutrientes contendo $0,28 \% \mathrm{Cu}, 7,5 \% \mathrm{Fe}, 3,5 \% \mathrm{Mn}, 0,7 \% \mathrm{Zn}$, $0,65 \%$ B e $0,3 \% \mathrm{Mo})$.

Cada parcela experimental foi constituída de uma bancada de aço com 0,64 $\mathrm{m}^{2}$ e 1,90 $\mathrm{m}$ de altura contendo um sistema hidropônico alternativo composto de 6 vasos plásticos de 3,0 $\mathrm{L}$, cujas bases eram perfuradas e equipadas com microtubos protegidos por tela, possibilitando a conexão individual a um reservatório coletor de solução nutritiva (um balde plástico com capacidade de $12 \mathrm{~L}$ ), constituindo o sistema de drenagem, sendo cada vaso preenchido com $10 \mathrm{~cm}$ de "sílica" (quartzo moído) na camada inferior e de $10 \mathrm{~cm}$ de substrato vermiculita na camada superior. A fim de diminuir a intensidade luminosa foi utilizada, sobre as parcelas experimentais e a 1,0 m de altura acima da cultura, uma malha termo-tefletora com $40 \%$ de atenuação da radiação solar. As parcelas experimentais foram alocadas em ambiente protegido do tipo capela com pé direito de 3,0 m, 12,0 m de comprimento e 16,0 m de largura, coberta com filme de polietileno de baixa densidade com aditivo antiultravioleta e espessura de 150 micras, protegida nas laterais com malha negra.

As mudas foram produzidas em bandejas de poliestireno expandido com 128 células preenchidas com vermiculita, as quais flutuavam em solução nutritiva na mesa de germinação. Realizou-se o transplante das mudas aos 16 dias após a semeadura, quando as plantas apresentaram de 5 a $6 \mathrm{~cm}$ de 
altura e 5 folhas definitivas, com emissão da sexta transplantando-se, aleatoriamente, uma muda por vaso, totalizando 3 plantas de cada cultivar por subparcela.

Diariamente e ao final da tarde a solução nutritiva era drenada dos vasos para o reservatório coletor, prática realizada por gravidade, ou seja, baixando-se o reservatório em nível menor que o dos vasos; na manhã seguinte, a solução nutritiva era retornada aos vasos, elevando-se o reservatório coletor a um nível maior que o dos vasos, sendo o procedimento de drenagem repetido ao meio-dia, visando à oxigenação do sistema.

A colheita foi realizada 24 dias após o transplantio para a realização das análises de produção: número de folhas (NF), determinado pela contagem de folhas verdes maiores de $3,0 \mathrm{~cm}$ de comprimento, desprezando-se as amareladas e/ou secas, partindo-se das folhas basais até a última folha aberta; matéria fresca da parte aérea (MFPA), estimada por pesagem em balança digital de precisão; matéria seca da parte aérea (MSPA), determinada pelo peso secado em estufa com circulação forçada de ar a $70^{\circ} \mathrm{C}$, até atingir peso constante, expresso em gramas, e área foliar (AF), utilizando-se o integrador de área foliar, modelo LI-3100 da Licor.

Os resultados foram interpretados pela análise de variância através do programa 'SISVAR' (Ferreira, 2000) para a comparação das médias de cada variável; daí, realizou-se a análise de regressão dessas médias. A produtividade percentual da alface em função da salinidade em cada tratamento foi calculada em relação à produtividade obtida com o tratamento testemunha. Os valores dos parâmetros de tolerância das culturas à salinidade SL (salinidade limiar) e b (perda de rendimento relativo por incremento unitário da condutividade elétrica da salinidade limiar) do modelo de Maas e Hoffman (1977) foram estimados com o programa SAS.

\section{RESULTADOS E DISCUSSÃO}

O número de folhas da alface foi significativamente influenciado pelos níveis de salinidade da solução nutritiva, apenas para a cultivar 'Verônica' (Figura 1A), registrando-se uma redução no número de folhas de $4,28 \%$ por incremento unitário, a partir da salinidade limiar de 4,28 dS m ${ }^{-1}$ (SL) (Figura 1B). Soares (2007), também verificou redução do número de folhas da alface hidropônica (cv. Elba) com o aumento da salinidade da solução nutritiva. No comparativo entre as cultivares 'Babá de verão' e 'Verônica', constatou-se que a primeira é mais tolerante ao incremento da salinidade da solução nutritiva, fato que pode explicar o efeito não significativo desta cultivar em resposta aos níveis de salinidade.

Investigação com a cultura da alface sob efeito da salinidade realizada por Gervásio et al. (2000), não relaciona a redução do número de folhas com o incremento da salinidade porém os autores observaram, a partir da CE $3 \mathrm{dS} \mathrm{m} \mathrm{m}^{-1}$, folhas com coloração verde-escuro, sem brilho e pouco tenras; as referidas observações podem estar relacionadas ao alto grau de salinidade presente na solução do solo.
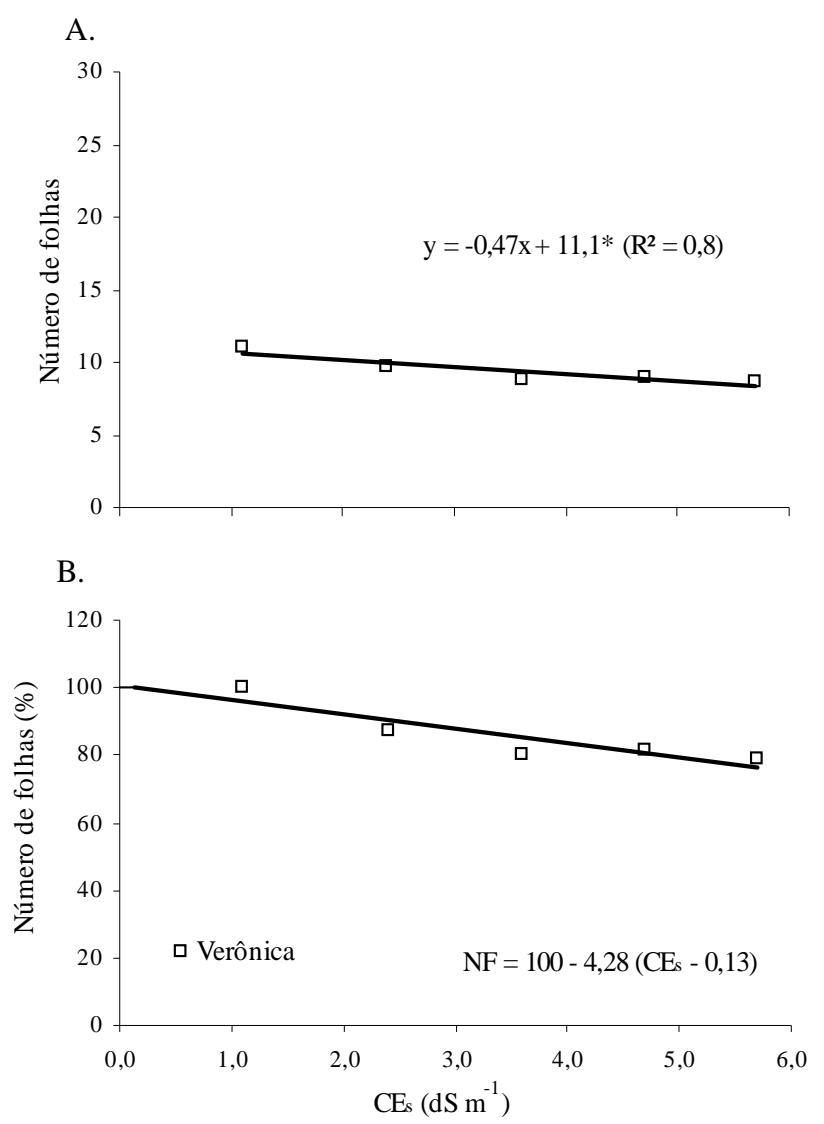

Figura 1. Comportamento da cultivar Verönica em sistema hidropônico para a variável número de folhas absoluto (A) e relativo (B) em função da variação da salinidade da solução (CEs)

A Figura 2 apresenta a relação entre MFPA e a CE da solução nutritiva demonstrando, para as duas cultivares estudadas, que a MFPA foi reduzida linearmente com o incremento da água de rejeito salino na solução nutritiva. Comparando-se os dados de salinidade limiar para as duas cultivares, observou-se uma salinidade limiar para a cultivar 'Babá de verão', de $0,94 \mathrm{dS} \mathrm{m}{ }^{-1}$, enquanto para a cultivar 'Verônica' este valor ficou em 1,30 dS $\mathrm{m}^{-1}$ (Figura 2B), sendo registradas perdas por incremento unitário a partir da SLde 4,28 e 6,68\% (dS m $\left.{ }^{-1}\right)$ para as cultivares 'Verônica' e 'Babá de verão', respectivamente, evidenciando que a tolerância das culturas varia entre cultivares de uma mesma espécie sendo que, nas condições em que a pesquisa foi desenvolvida, a cultivar 'Verônica' foi mais tolerante a salinidade da solução nutritiva com rejeito salino. Gervásio et al. (2000) encontraram, trabalhando com a cultivar Alface americana, outros valores de limiar de salinidade, sendo que a inclinação das curvas da produção total se equipara com a apresentada por Maas \& Hoffman (1977), porém com salinidade limiar bastante reduzida, 0,2 contra 1,3 $\mathrm{dS} \mathrm{m}^{-1}$ encontrada pelos citados autores. Os referidos valores ficaram mais próximos daqueles encontrados por Mass \& Hoffman (1977) e podem ser creditados à ausência do potencial mátrico do solo do cultivo hidropônico, demonstrando a vantagem deste sistema em relação ao cultivo convencional, quando se utilizam águas salobras.

Com relação à matéria seca da parte aérea, contatou-se efeito significativo com redução da matéria seca por aumento da 

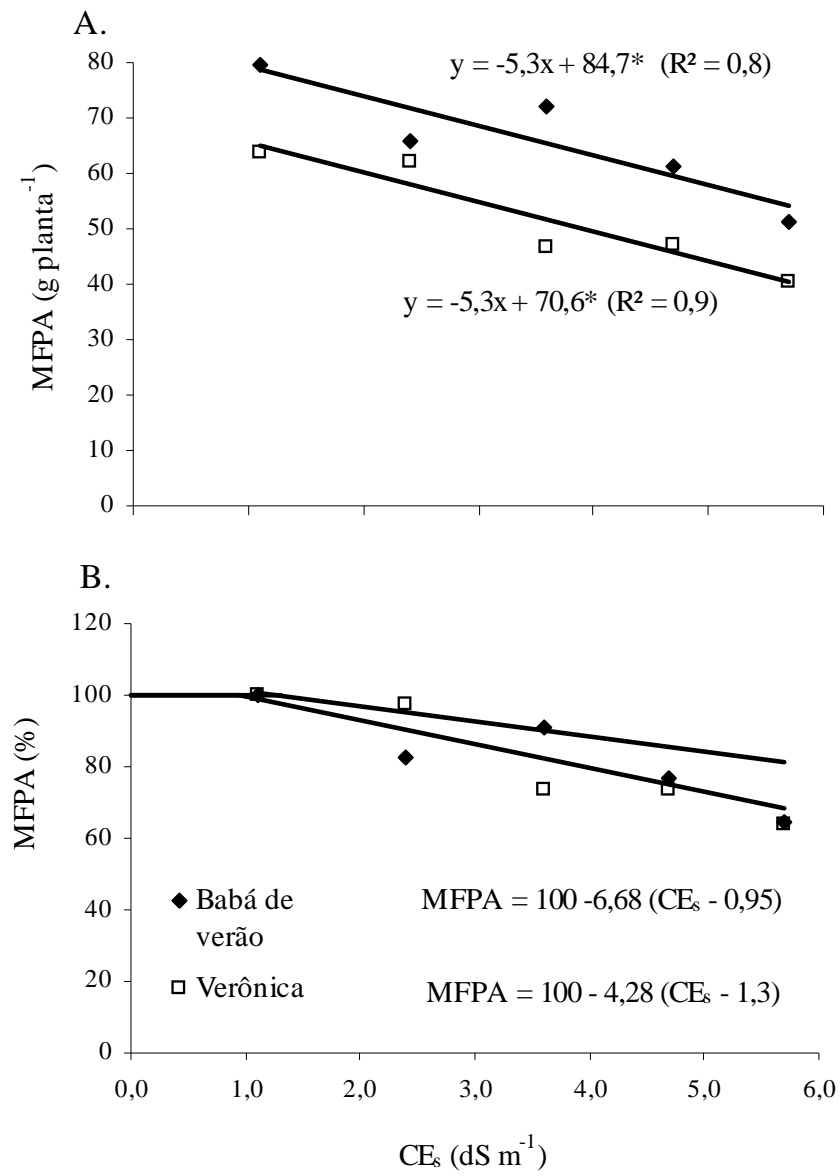

Figura 2. Comportamento das duas cultivares de alface em sistema hidropônico para a variável matéria fresca da parte aérea (MFPA) absoluto ( $A$ ) e relativo (B) em função da variação da salinidade da solução (CEs)

salinidade da solução nutritiva (Figura 3), porém quando se comparam as variáveis MFPA e MSPA, verificam-se comportamentos diferentes entre as duas cultivares, ou seja, a cultivar 'Babá de verão' mostrou-se com menor perda relativa de MSPA em relação à perda de MFPA, representadas pelos coeficientes "b" do modelo de Maas e Hoffman, que foram 5,48 e $6,68 \%\left(\mathrm{dS} \mathrm{m}^{-1}\right)^{-1}$ para a MSPA e MFPA, respectivamente; já para a cultivar 'Verônica' ocorreu comportamento contrário, isto é, a perda relativa de MSPA $(b=7,83)$ foi superior à perda relativa de MFPA $(b=4,28)$ como mostram as Figuras 2 e 3.

Viana et al. (2001) obtiveram resultados semelhantes quando verificaram uma redução maior da matéria seca da parte aérea em relação à redução da matéria fresca da alface, respectivamente de 27 e $25,3 \%$ as reduções do maior nível de salinidade $\left(3,1 \mathrm{dS} \mathrm{m}^{-1}\right)$ em relação ao tratamento testemunha $\left(0,3 \mathrm{dS} \mathrm{m}^{-1}\right)$.

A área foliar sofreu efeito significativo da salinidade a $1 \%$ de probabilidade para ambas as cultivares estudadas (Figura 4A) o que, certamente, contribuiu para a redução das massas de matérias fresca e seca da parte aérea. A cultivar 'Verônica' apresentou redução de $9,08 \%$ por acréscimo unitário da CEs e perda total do maior nível de salinidade em relação à testemunha, de 37,10\%; para a cultivar 'Babá de verão' essas reduções foram de 8,47 e $38,96 \%$ respectivamente, como mostra a Figura 4B.

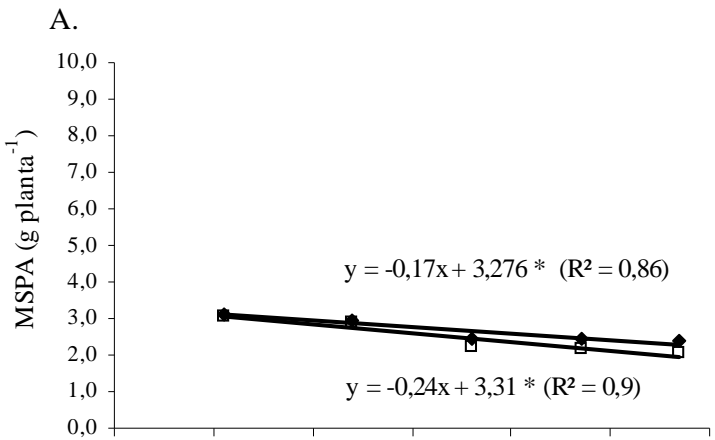

B.

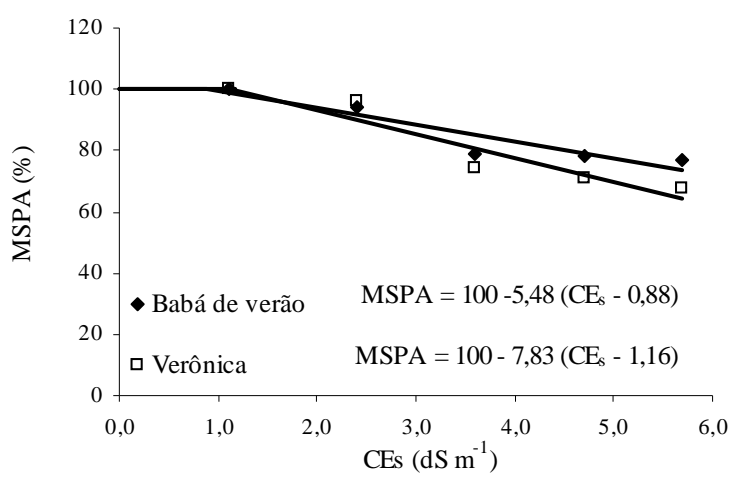

Figura 3. Comportamento das duas cultivares de alface em sistema hidropônico para a variável matéria seca da parte aérea (M SPA), absoluto (A) e relativo (B), em função da variação da salinidade da solução (CEs)

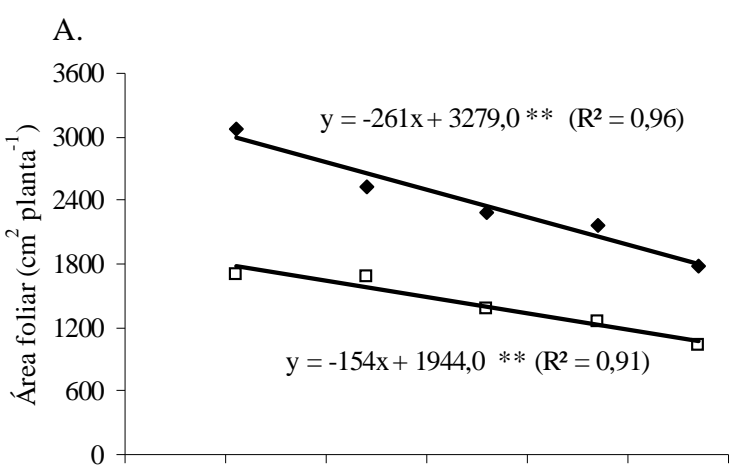

B.

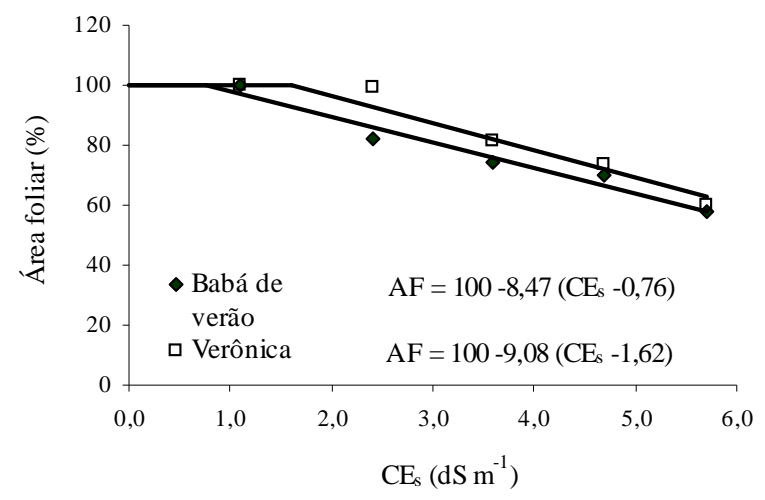

Figura 4. Comportamento das duas cultivares de alface em sistema hidropônico para a variável matéria fresca da parte aérea (MFPA) absoluto (A) e relativo (B) em função da variação da salinidade da solução (CEs) 
O decréscimo da área foliar decorre, provavelmente, da diminuição do volume de células e, segundo Mittova et al. (2002) e Sultana et al. (2002), as reduções de área foliar e de fotossíntese contribuem, de certo modo, para adaptação da cultura à salinidade; a redução da área foliar sob estresse hídrico pode ser um mecanismo de sobrevivência que permite a conservação de água pela menor área transpiratória das plantas.

\section{ConclusõEs}

1. A alface mostrou-se sensível ao incremento da salinidade da solução nutritiva com rejeito salino, reduzindo o número de folhas, a área foliar e a massa de matéria fresca e seca da parte aérea, para as duas cultivares estudadas.

2. Houve variação genotípica sob as variáveis de crescimento e produção da alface em hidroponia, exceto para o número folhas, sendo a cultivar 'Babá de verão' a que produziu maior rendimento, independentemente do nível de salinidade sendo, portanto, a cultivar mais tolerante à salinidade da água com rejeito salino.

\section{LITERATURA CITADA}

Al-Karaki, G.; Al-Ajmi, A.; Othman, Y. Response of soilless grown bell pepper cultivars to salinity. Acta Horticulturae, v.807, p.227-232, 2009.

Amorim, M. C. C.; Porto, E. R.; Silva Júnior, L. G. A. Evaporação solar como alternativa de reuso dos efluentes da dessalinização por osmose inversa. http://www.cepis.org.pe /bvsaidis/aresidua/i-007.pdf. 30 Set. 2004.

Ayers, R. S.; Westcot, D. W. A qualidade da água na agricultura. Estudos FAO. Irrigação e Drenagem 29 (Revisado). Campina Grande: UFPB. 1999. 218p.

Caruso, G. Villari, G. Effect of EC-level and plant shading on the NFT-grown "Friariello pepper". Acta Horticulturae, v.659, p.576-585, 2004.

Ferreira, D. F. Manual do sistema Sisvar para análises estatísticas. Lavras: UFV, 2000. 66p.
Gervásio, E. S.; Carvalho, J. A.; Santana, M. J. Efeito da salinidade da água de irrigação na produção da alface americana. Revista Brasileira de Engenharia Agrícola e Ambiental, v.4, p.125-128, 2000.

Maas, E. V.; Hoffman, G. J. Crop salt tolerance: current assessment. Journal of irrigation and. Drainage Division ASCE, v.103, n. IR2, p.115-134, 1977.

Mittova, V.; Tal, M.; Volokita, M.; Guy, M. Salt stress induces up-regulation of an efficient chloroplast antioxidant system in the salt-tolerant wild tomato species but not in the cultivated species. Physiologia Plantarum, v.115, p.393-400, 2002.

Porto, E. R., Amorim, M. C. C. de; Silva Júnior, L. G. A. Uso do rejeito da dessalinização de água salobra para irrigação da erva-sal (Atriplex nummularia). Revista Brasileira de Engenharia Agrícola e Ambiental, v.5, p.111-114, 2001.

Riley, J. J.; Fitzsimmons, K. M.; Glenn, E. P. Halophyte irrigation: an overlooked strategy for management of membrane fraction concentrate. Desalination, v.110, p.197-211. 1997.

Savvas, D., Stamati, E., Tsirogirogianvis, I. L., Mantzos, N., Barouchas, P.E., Katsoulas, N. and Kittas, C. Interactions between salinity and irrigation frequency in greenhouse pepper grown in closed-cycle hydroponic systems. Agricultural Water Management, v.91, p.102-111, 2007.

Soares, T. M. Utilização de águas salobras no cultivo da alface em sistema hidropônico NFT como alternativa agrícola condizente ao semi-árido brasileiro. Piracicaba: ESALQ/USP. 2007. 268p. Tese Doutorado

Soares, T. M.; Silva, I. J. O. da; Duarte, S. N.; Silva, Ê. F. de F. e. Destinação de águas residuárias provenientes do processo de dessalinização por osmose reversa. Revista Brasileira de Engenharia Agrícola e Ambiental, v.10, p.730-737, 2006.

Sultana, N.; Keda, T.; Kashem, M. A. Effect of seawater on photosynthesis and dry matter accumulation in developing rice grains. Photosynthetica, v.40, p.115-119, 2002.

Viana, S. B. A.; Rodrigues, L. N; Fernandes, P. D.; Gheyi, H. R. Produção da alface em condições de salinidade a partir de mudas produzidas com e sem estresse salino. Revista Brasileira de Engenharia Agrícola e Ambiental, v.5, p.62-66, 2001. 